\title{
De cognitieve functie van contracteren: naar een beter begrip van partners
}

Paul W.L. Vlaar, Henk W. Volberda en Frans A.J , van den Bosch

SAM ENVATTING Onderzoek naar contractgebruik in interorganisatorische relaties, zoals allianties, joint ventures en outsourcing initiatieven, richt zich tot op heden voornamelijk op motivatie- en coördinatievraagstukken. In dit artikel stellen wij dat de onderhandelingsen contracteringsprocessen ook functioneren als middel om bewustwording en begrip te creëren. Door formele onderhandelingen te voeren, contracten te schrijven en discussies aan te gaan, scheppen contractpartijen bijvoorbeeld meer duidelijkheid over de mogelijkheden en beperkingen van een relatie, de middelen waarover beide partijen beschikken en hun intenties en belangen. Deze cognitieve functie van onderhandelings- en contracteringsprocessen heeft verschillende positieve effecten op de prestaties van samenwerkingsverbanden, waaronder: (i) betere expliciete beheersing en coördinatie; (ii) sterkere impliciete beheersing en coördinatie; (iii) beperking van onbegrip en misinterpretatie; en (iv) betere mogelijkheden voor het identificeren van kansen om samen waarde te creëren.

\section{RELEVANTIE VOOR DE PRAKTIJ $K$ Dit artikel draagt bij aan een beter beeld van de cognitieve functie van contracten en pre-formatieprocessen in interorganisatorische relaties. Onderzoekers, managers en adviseurs kunnen het door ons gepresenteerde integrale raam- werk gebruiken om onderhandelings- en contracteringsprocessen op een andere manier vorm te geven en niet alleen aandacht te schenken aan de coördinatie- en beheersingsfunc- tie van contracten, maar ook aan de overeenkomsten en verschillen in cognitieve represen- taties die hiermee samenhangen. Controllers spelen in dit verband een belangrijke rol, omdat zij veelal beschikken over een 'helicopter view'. Dit zorgt ervoor dat zij meestal goed in staat zijn om de betekenis van een interorganisatorische relatie voor interne bedrijfspro- cessen en de financiën van hun organisatie te bepalen.}

\section{Inleiding}

Interorganisatorische relaties, zoals allianties, joint ventures en oursourcing-initiatieven brengen coördinatie en beheersingsvraagstukken met zich mee. Potentiële partners stellen daarom normaliter formele contracten op, waarin zij afspraken vastleggen rondom de rechten en plichten van beide partijen en de onderlinge afstemming van activiteiten, processen en gedragingen. In de literatuur wordt daarom veelvuldig gesproken over de coördinatie en beheersingsfunctie van contracten. In dit artikel betogen wij dat de onderhandelings- en contracteringsprocessen die tot formele afspraken leiden echter nog een derde functie hebben, die in de literatuur onderbelicht is gebleven. Het betreft hier de cognitieve functie van contracten en de processen die tot contracten leiden.

Om deze functie uiteen te kunnen zetten, is het allereerst van belang om een helder beeld te schetsen van de eerste fase van een samenwerkingsverband. In veel gevallen leggen potentiële partners contact met elkaar zonder dat zij eerder hebben samengewerkt. Soms zijn zij bovendien werkzaam in andere sectoren of industrieën en in veel gevallen bestaan er aanmerkelijke verschillen in bedrijfsculturen, ondernemingsstructuren en activiteiten. Deze verschillen en de relatieve onbekendheid met het andere bedrijf zorgen ervoor dat, hoewel partijen intuïtief beseffen dat er mogelijkheden bestaan om samen waarde te creëren, er vaak nog weinig bekend is over hoe dit dient te geschieden.

Het kan bijvoorbeeld onduidelijk zijn over welke competenties beide partners precies beschikken en welke activiteiten er nodig zijn om complementaire hulpbronnen en vaardigheden daadwerkelijk met elkaar te combineren. Ook is het niet altijd evident waarom potentiële partners precies heil zien in een relatie, wat hun motivaties en belangen zijn en hoe zij zich in de relatie zullen opstellen. Andere vraagtekens betreffen bijvoorbeeld de uiteindelijke verdeling van de opbrengsten, de beperkingen waarmee partners zich geconfronteerd zien en de mate waarin medewerkers van beide organisaties zich gecommitteerd zullen voelen aan de relatie. Daarnaast zorgen de verschillen tussen partners er voor dat zij dezelfde waarnemingen anders interpreteren en begrijpen (Porac et al. 2002; Sutcliffe en Huber 1998; Vaara 2003).

Onderhandelings- en contracteringsprocessen helpen deelnemers aan interorganisatorische relaties om een beter beeld te verkrijgen van hun partners, het samenwerkings- 
verband en de omgeving waarin deze is ingebed. Zij vormen derhalve een proces van 'zingeving', een concept dat centraal staat in het werk van Karl Weick $(1969,1995,2001)$. Zingeving verwijst in dit kader naar de processen waardoor deelnemers in interorganisatorische relaties proberen hun directe omgeving te begrijpen om vanuit dat begrip tot gezamenlijke actie over te gaan (Maitlis 2005; Weick en Roberts 1993).

Doordat onderhandelings- en contracteringsprocessen zingeving bevorderen, stellen zij partijen met 'verschillende visies op de doelen en verwachtingen van een relatie in staat om overeenstemming te bereiken' (Ring en Van de Ven 1994: 99) en om een beter beeld te verkrijgen van hun partner, de relatie zelf en de omgeving waarin deze is ingebed. Dit wordt ondersteund door Blomqvist et al. (2005: 497), die stellen dat 'het contractvormingsproces [...] kan worden gebruikt om wederzijds begrip te vergroten'. Deze auteurs beschrijven bijvoorbeeld hoe een leverancier van machines en apparatuur en een metaalontwerp bedrijf 'elkaar leerden kennen vanwege het langdurige contractvormingsproces' (Blomqvist et al., 2005: 502).

\section{Zingeving in relatie tot onderhandelings- en contracteringsprocessen}

Onderhandelings- en contracteringsprocessen stellen partners via ten minste vier mechanismen in staat om zin te geven aan waarnemingen betreffende de partner, de relatie en de context waarin deze is ingebed (Vlaar et al. 2006). Ten eerste zorgen deze processen ervoor dat deelnemers aan interorganisatorische relaties hun aandacht focussen op de keuzes en besluiten die gemaakt dienen te worden (Weick 2001), en dat zij afbakenen wat toegestaan, verwacht, aanvaardbaar en mogelijk is en wat niet (Carson et al 2006; Lui en Ngo 2004; Nellore 2001). Ze helpen om sommige kwesties selectief te benadrukken en anderen juist te marginaliseren of weg te laten (Fiss en Zajac 2006). Ook voorkomen deze processen dat deelnemers worden afgeleid van kwesties van secundair belang (Delmar en Shane 2003).

Hierdoor kunnen deelnemers aan deze processen zich geleidelijk richten op een beperkt aantal zaken en probleemgebieden, waardoor de cognitieve complexiteit die zij ervaren, afneemt (Boisot en Child 1999; Campbell 1988). Een voorbeeld betreft de onderhandelingen en contractvorming in een alliantie tussen Xerox en Fuji Xerox. De leidinggevende van Xerox in deze alliantie claimde dat de onderhandelende teams ieder detail hadden besproken. Hij merkte op dat 'vele intelligente mensen alle wegen hadden bewandeld op zoek naar mogelijke toekomstige problemen', en dat ze hun tijd hadden besteed 'aan het doorspitten van alle "wat als" vragen'. Ze 'haalden voortdurend de overeenkomst uit elkaar en voegden deze weer samen' (Gomes-Casseres 1996:27).
Een tweede factor die verklaart waarom onderhandelingsen contracteringsprocessen zingeving stimuleren, bestaat uit de noodzaak die deze processen met zich meebrengen om kennis, assumpties en verwachtingen uit te spreken, heldere afwegingen te maken en te reflecteren. Deelnemers aan dergelijke processen worden aangespoord om expliciet te maken wat hen bezig houdt in relatie tot het samenwerkingsverband. Dit verduidelijkt hun identiteit, standpunten en het type gedrag dat zij prefereren (Shankarmahesh et al. 2004).

Op individueel niveau worden mensen bovendien min of meer gedwongen om te reflecteren, zaken te overdenken en dieper na te denken (Weick 1995; Zollo en Winter 2002). Onderhandelings- en contracteringsprocessen stimuleren hen om overwegingen te maken die verder gaan dan algemene inzichten en om duidelijkheid te scheppen over de variabelen en parameters die van belang zijn in het kader van de relatie (Katz en Kahn 1966). Dit wordt versterkt door het feit dat deelnemers zich gedurende dit soort processen meestal proberen zich nauwkeurig uit te drukken en zorgvuldig te formuleren (Gouldner 1954: 162). Een voorbeeld bestaat uit de relatie tussen een software bedrijf uit Silicon Valley en een Japanse elektronicaproducent waar een sectie over 'risico's en potentiële problemen' was opgenomen in formele stukken teneinde 'de deelnemers te dwingen hun project goed te overdenken' (Mayer en Argyres 2004: 400).

Een derde mechanisme waardoor onderhandelings- en contracteringsprocessen zingeving faciliteren, bestaat uit het feit dat deze processen aanzetten tot interactie en communicatie tussen partners en deelnemers aan een relatie. Deze processen hangen sterk samen met 'reeksen van formele processen' en uitkomsten (Ring 2000: 154) die dienen als kaders, media of drijfveren voor interactie (Ness 2002; Putnam 2003). Deze worden gebruikt om nieuwe verhalen te creëren; nieuwe acties in gang te zetten; mijlpalen en startpunten aan te kondigen; en natuurlijk veranderingen in werking te stellen (Avadikyan 2001; Eccles en Nohria 1992; Weick 1995).

Ze veroorzaken ook de uitwisseling van voorstellen tussen partijen en bevorderen daarmee conversaties en dialogen (Nellore 2001; Putnam 2003) en ze maken het mogelijk besprekingen te voeren over taken die nog niet zijn uitgevoerd en over resultaten die nog moeten worden geboekt (Yakura 2002). Door te argumenteren, luisteren en discussiëren worden deelnemers aan relaties in staat gesteld 'hun meningen en overtuigingen te uiten, zich bezig te houden met constructieve confrontatie en elkaars visies te betwisten' (Zollo en Winter 2002: 341). Een voorbeeld betreft samenwerkingsverbanden van OEM-producenten in de auto- en luchtvaartuigindustrie, waar contracten een kader voor discussie vormden dat partners in staat stelde 'de specificaties, elkaars bekwaamheden en de benodigde middelen voor de taak te begrijpen' (Nellore 2001: 502). 
Figuur 1 De cognitieve functie van contracten: implicaties voor samenwerkingsverbanden

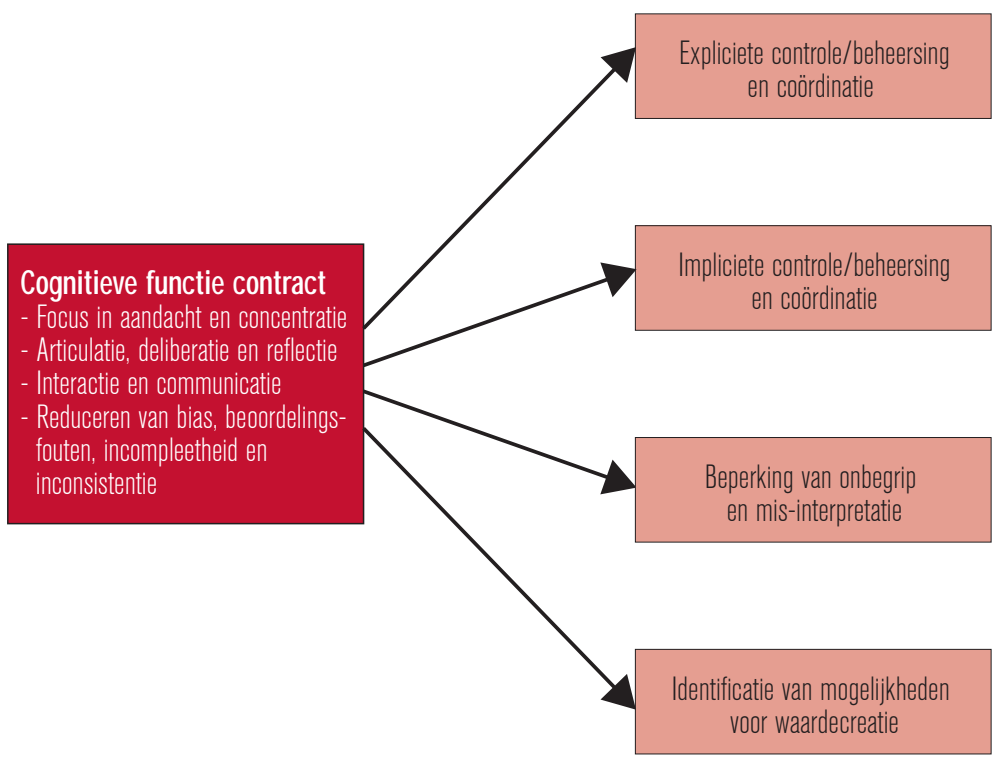

Ten slotte katalyseren onderhandelings- en contracteringsprocessen zingeving door voordelen, individuele beoordelingsfouten, incompleetheid en inconsistentie met betrekking tot het beeld dat binnen organisaties bestaat van een partner, de relatie en de context waarin deze is ingebed, te reduceren. Deze processen worden namelijk gevoed door de ideeën en interesses van meerdere personen en compenseren daarmee de beperkingen en tekortkomingen van de mentale kracht van individuen (Katz en Kahn 1966; Ketokivi en Catañer 2004). Ook verhoogt het de kans dat relevante informatie naar behoren wordt overwogen en dat inconsistenties in gedachtepatronen worden ontdekt en geëlimineerd (Avadikyan et al. 2001; Sutcliffe en McNamara 2001). Dit leidt tot een genuanceerder, volmaakter en consistenter beeld van de realiteit (Katz and Kahn 1966).

Dit wordt versterkt door het feit dat contracten vereisen dat partijen relatief eenduidige bepalingen voor gewenst gedrag en uitkomsten bevatten, zodat afwijkingen duidelijk verifieerbaar zijn (Carson et al. 2006). Een voorbeeld is de alliantie tussen L'Oréal en Esthetique, waarbij toevoegingen aan het contractuele kader 'op alle niveaus van interactie "ruis" reduceerde' (Ness 2002: 25). Een voorbeeld van een contrasterende situatie refereert aan de alliantie tussen Ciba Geigy en Alza, gericht op de ontwikkeling van gecontroleerde orale pillen en transdermale pleisters. Hier liet 'de aanvankelijke overeenkomst ruimte open voor [...] zeer uiteenlopende waarnemingen en brede kaders [die] leidden tot toenemend wantrouwen en spanningen, waarbij beide partijen op zoek waren naar aanwijzingen in het gedrag van de ander' (Doz 1996: 68).

\section{Effecten op de prestaties van samenwerkings- verbanden}

Onze beschrijving van onderhandelings- en contracteringsprocessen als katalysatoren van begrip in samenwerkingsverbanden vormt een opstap naar een uiteenzetting van de effecten die deze cognitieve functie van contracten met zich meebrengt. Deze invloeden worden in Figuur 1 grafisch weergegeven. Zij bestaan uit: (i) betere mogelijkheden voor expliciete beheersing van gedrag en uitkomsten binnen relaties, alsmede betere mogelijkheden voor expliciete coördinatie, ofwel afstemming van activiteiten, middels regels, procedures en andere formele afspraken; (ii) sterkere impliciete beheersing en een hogere mate van impliciete coördinatie; (iii) beperking van onbegrip en misinterpretatie; en (vi) een grotere kans dat partners mogelijkheden voor het gezamenlijk creëren van waarde binnen het samenwerkingsverband identificeren en onderzoeken (zie ook Vlaar, 2008).

\subsection{Betere mogelijkheden tot expliciete beheersing en coördinatie}

Wederzijds begrip van participanten in interorganisatorische relaties biedt allereerst betere mogelijkheden voor expliciete beheersing van het gedrag van partners en de uitkomsten verbonden aan samenwerkingsverbanden in regels, procedures en andere formele overeenkomsten (Mayer en Argyres, 2004). Doordat partijen meer van elkaar weten, is het eenvoudiger te bepalen welke risico's ieder van hen loopt en hoe deze afgedekt kunnen worden.

Het is bovendien makkelijker in te schatten óf en op welk gebied partners zich in de toekomst opportunistisch zouden kunnen gaan gedragen. De mate van informatieasymmetrie tussen partners is daarnaast beperkter, waardoor de eenzijdige exploitatie van (voor)kennis wordt beknot. Ook de verhouding tussen de rechten en plichten van contractpartijen en de mate waarin deze als 'fair' kan worden beschouwd, is duidelijker. Dit stelt partners in samenwerkingsverbanden in staat om betere toepasbare en sterker gefundeerde afspraken te maken met betrekking tot de inspanningen die door ieder worden geleverd, de activiteiten die worden ondernomen en de verdeling van kosten, opbrengsten en risico's.

Hetzelfde geldt voor de mogelijkheid om formele afspraken met betrekking tot de coördinatie of afstemming van activiteiten expliciet vast te leggen. Wanneer partners een beter beeld hebben van elkaar, de relatie en hun omgeving, kunnen zij makkelijker bepalen 'wie' van hen 'wat' moet doen en 'wanneer' dit dient te geschieden. Het wordt eenvoudiger om processen en activiteiten te definiëren en om te beschrijven hoe deze zich tot elkaar verhouden en in welke volgorde ze dienen plaats te vinden.

Daarnaast kan de benodigde tijd voor de uitvoering van taken beter en eenduidiger worden gespecificeerd. Ook is 
het eenvoudiger om te registreren hoe communicatie- en informatiestromen behoren te verlopen en om te beschrijven welke personen en afdelingen daarbij betrokken zijn. Een hogere mate van begrip voortkomend uit onderhandelings- en contracteringsprocessen vindt derhalve zijn weerslag in beter toepasbare en specifieker geformuleerde contracten regels en procedures ten behoeve van beheersing en coördinatie in interorganisatorische relaties (zie ook Vlaar, 2008).

\subsection{Sterkere impliciete beheersing en coördinatie}

Hoewel partners die een hogere mate van begrip vertonen beter in staat zouden moeten zijn om expliciete, formele afspraken over beheersing- en coördinatievraagstukken te maken, zorgt een hogere mate van begrip er paradoxaal genoeg ook voor dat zij een beperktere behoefte kunnen ervaren om zaken formeel vast te leggen. Een beter onderling begrip leidt er namelijk toe dat opportunistisch gedrag van de ander 'doorzichtiger' is en eerder wordt ontdekt. Ook is het makkelijker om te bepalen of een partner open en eerlijk is, beschikbare informatie deelt, zaken achterhoudt of duistere bijbedoelingen heeft.

Bovendien zijn partners minder goed in staat om 'private' voordelen of positieve spillovers voor hun organisatie, voortkomend uit de relatie buiten de discussie over waardecreatie en waardeappropriatie, te houden, waardoor dit minder snel een probleem vormt in de ex post-fase van interorganisatorische relaties. Deze factoren zorgen ervoor dat partijen geneigd zijn om eerder af te zien van opportunistisch gedrag, waardoor er minder behoefte bestaat aan expliciete afspraken. In feite vertegenwoordigt een beter onderling begrip dus een vorm van zelfregulering, welke wordt aangeduid met de term impliciete beheersing.

Een vergelijkbaar effect geldt voor de coördinatie tussen partners in samenwerkingsverbanden. Doordat partners elkaar beter begrijpen, hoeven deelnemers aan dergelijke relaties niet noodzakelijkerwijs hun activiteiten af te stemmen door middel van formele documenten. Coördinatie vindt veeleer plaats op basis van observatie, anticipatie en onderlinge afstemming gedurende activiteiten en processen (Rico et al. 2008). Indien deelnemers aan samenwerkingsverbanden een beter beeld hebben van de structuur en activiteiten van partners is het soms bijvoorbeeld onnodig om de volgorde en lengte van activiteiten gedetailleerd vast te leggen, omdat beide partijen al weten wanneer en hoe ze moeten handelen.

De opeenvolging en overdracht van activiteiten wordt in dit geval vaak gezien als 'logisch' en partners schieten 'automatisch' te hulp wanneer zij zien dat dit nodig is. Activiteiten worden 'naadloos' overgenomen en partijen weten van elkaar wanneer zij aan de beurt zijn om iets te doen of op te leveren. Concluderend stellen wij dat een hogere mate van begrip voortkomend uit onderhande- lings- en contracteringsprocessen leidt tot een sterkere mate van impliciete beheersing en coördinatie.

\subsection{Beperking van onbegrip en misinterpretatie}

Door het begrip dat deelnemers aan interorganisatorische relaties hebben van hun partner, de relatie zelf en de omgeving waarin deze is ingebed, verkleinen onderhandelingsen contracteringsprocessen ook de kans dat relaties worden gekenmerkt door onbegrip en misinterpretatie. Een fijnmazig beeld van de cultuur, het management systeem, de hulpbronnen, vaardigheden, zwaktes, ambities en verwachtingen van partners, alsmede een beter inzicht in de aard van de taart die samen kan worden gecreëerd binnen de relatie en de activiteiten die hiervoor dienen te worden ondernomen (Jap 2001), bieden een sterke basis voor gezamenlijke actie (Maitlis 2005; Weick en Roberts 1993). Omdat partijen beschikken over een collectief bewustzijn, een gelijkluidend beeld van de realiteit, of gedeeld begrip van hun directe omgeving, zullen zij gebeurtenissen makkelijker kunnen duiden en wordt het waarschijnlijker dat zij deze op vergelijkbare wijze interpreteren. Participanten vinden het in dit geval minder moeilijk om het gedrag van de partnerorganisatie te plaatsen en het wordt onwaarschijnlijker dat zij geconfronteerd worden met misverstanden, aangezien zij vanuit een sterker overeenkomend denkkader waarnemen, interpreteren en redeneren (Vlaar et al. 2006).

\subsection{Identificeren van gezamenlijke kansen voor waardecreatie}

Ten slotte zorgt een hogere mate van begrip voortkomend uit onderhandelings- en contracteringsprocessen voor een grotere kans dat partners gezamenlijke mogelijkheden voor waardecreatie identificeren (zie Vlaar, 2008). Door een beter begrip wordt het eenvoudiger om te bepalen welke competenties binnen de relatie kunnen worden ingezet en welke activiteiten er nodig zijn om de complementariteit van hulpbronnen en vaardigheden te effectueren. Ook kunnen partners makkelijker bestaande kennis in beide organisaties met elkaar hercombineren, omdat zij weten dat deze beschikbaar is en omdat ze beter in staat zijn om te beoordelen dat deze relevant voor de relatie is.

Een beter begrip vergroot bovendien het gemak waarmee partners informatie met elkaar kunnen delen en waarmee ze van elkaar kunnen leren. Dit zorgt ervoor dat partners meer kansen en mogelijkheden voor gezamenlijke activiteiten ontdekken. Het wordt eenvoudiger voor hen om te bepalen hoe combinaties van hulpbronnen en vaardigheden kunnen worden gerealiseerd, die tegemoet komen aan een latente vraag in de markt (zie ook Foss en Klein, 2008). Op vergelijkbare wijze zorgt een beter begrip voor een duidelijker beeld van de beperkingen waarmee de partners in hun relatie te maken krijgen en de sterktes waarop zij zouden kunnen voortbouwen om samen waarde te creëren. 


\section{Discussie}

In dit artikel hebben we uiteengezet dat onderhandelingsen contracteringsprocessen in samenwerkingsverbanden niet alleen dienen om beheersing en coördinatie te bewerkstelligen, maar dat zij ook functioneren als middel om bewustwording en begrip te creëren. We hebben daarbij de socio-psychologische aspecten benadrukt die verbonden zijn met deze processen, welke de betrokken personen in staat stellen een beter beeld te construeren van de partner, de relatie zelf en de omgeving waarin deze is ingebed.

Vervolgens zijn we ingegaan op de wijze waarop de cognitieve functie van contracten de prestaties van samenwerkingsverbanden beïnvloedt. We hebben hierbij een onderscheid gemaakt in vier effecten:

1. Betere expliciete beheersing en coördinatie;

2. Sterkere impliciete beheersing en coördinatie;

3. Reductie van onbegrip en misinterpretatie;

4. Betere mogelijkheden voor het identificeren van kansen.

Dit artikel draagt bij aan een scherper beeld van de cognitieve functie van contracten en pre-formatieprocessen in interorganisatorische relaties. De implicaties voor onderzoekers zijn tweeledig. Allereerst ontwikkelen we in het artikel een integraal raamwerk van de prestatie-effecten die samenhangen met de cognitieve functie van contracten. Tot op heden zijn deze invloeden altijd separaat beschreven en geanalyseerd (zie bijvoorbeeld Vlaar, 2008; Vlaar et al. 2006, 2008). We laten zien dat beter begrip voorkomend uit onderhandelings- en contracteringsprocessen bijdraagt aan het voorkomen van problemen en conflicten in relaties (i.e. de reductie van onbegrip en misinterpretaties), het soepeler laten verlopen van interactieprocessen (i.e. betere expliciete en sterkere impliciete beheersing en coördinatie) en het verhogen van de kans dat partners opties zien om binnen de relatie meerwaarde te creëren (i.e. het identificeren van kansen).

Academici kunnen dit raamwerk gebruiken om onderzoeken te ontwerpen waarin de verschillende effecten van contracten en onderhandelings- en contracteringsprocessen tegen elkaar worden afgezet. Vragen die aan de orde zouden kunnen komen zijn onder meer: 'Wat is belangrijker: de processen of de contracten zelf?' 'Welke effecten van de cognitieve functie van contracten wegen het zwaarst?' 'In welke mate wordt onderling begrip bepaald door onderhandelings- en contracteringsprocessen?' 'Hoe verhouden deze processen zich tot het geschreven contract zelf en tot de psychologische contracten in de hoofden van de deelnemers in samenwerkingsverbanden?' Een tweede academische contributie van het artikel bestaat uit de verschuiving die het bewerkstelligt in de aandacht van wetenschappers voor de capaciteiten, motieven en belangen van de deelnemers aan samenwerkingsverbanden, naar hun denkbeelden, interpretaties en percep- ties. Hiermee ondersteunt het eerder onderzoek waarin het belang van begrip en cognitie in zijn algemeenheid voor interorganisatorische relaties wordt benadrukt (zie bijvoorbeeld Foss, 1999; Kumar en Anderson, 2000; Thomas and Trevino, 1993; Vlaar, 2008; Vlaar et al., 2006, 2008). Ons raamwerk suggereert dat onderzoekers niet langer alleen de gedragingen, activiteiten en uitkomsten binnen samenwerkingsverbanden dienen te bestuderen, maar ook de overeenkomsten en verschillen in de cognitieve representaties die participanten in dergelijke relaties van deze zaken ontwikkelen.

Voor managers en adviseurs, alsmede deelnemers aan samenwerkingsverbanden binnen en buiten organisaties, betekent ons betoog dat zij onderhandelings- en contracteringsprocessen kunnen benutten om een beter inzicht te verkrijgen in de mogelijkheden en problemen die relaties met zich mee kunnen brengen. Aangezien een hogere mate van begrip zich ook vertaald in: (i) sterkere impliciete en meer adequate expliciete beheersing en coördinatie, (ii) een afname van onbegrip, misinterpretatie en conflicten (iii) en betere mogelijkheden voor het identificeren van kansen, verdient het de aanbeveling om veel tijd te besteden aan deze processen.

Ook pleit onze discussie het voor prominente betrokkenheid van sleutelfiguren aan beide kanten van samenwerkingsverbanden gedurende het onderhandelen over en schrijven van contractbepalingen. Dit voorkomt dat bedrijfsjuristen en advocaten, die soms de boventoon voeren bij de totstandkoming van externe relaties, een contract dichttimmeren dat is gestoeld op sterk verschillende visies van partners en dat diegenen die de relatie moeten vormgeven en managen relatief onwetend zijn betreffende de mogelijkheden en onmogelijkheden die samenhangen met de relatie.

Controllers spelen in dit verband een belangrijke rol. Zij zijn over het algemeen goed op de hoogte van de belangrijkste bedrijfsprocessen en beschikken veelal over een 'helicopter view'. Hierdoor overzien ze snel de financiële en organisatorische implicaties van gezamenlijke initiatieven met andere ondernemingen en kunnen ze als geen ander een bijdrage leveren aan onderhandelings- en contracteringsprocessen. Dit vereist wel van de controller dat deze een open houding aanneemt en noodzakelijke veranderingen in de eigen organisatie en administratie ten gevolge van een interorganisatorische relatie beoordeeld vanuit het belang van de organisatie als geheel en niet alleen vanuit de eigen afdeling die veelal is gericht op efficiëntie, standaardisering en kostenbeheersing.

\section{Conclusie}

Waar onderzoek naar contractgebruik in interorganisatorische relaties zich tot op heden met name richt op motivatie- en coördinatievraagstukken hebben wij in dit artikel 
uiteengezet hoe onderhandelings- en contracteringsprocessen bijdragen aan de ontwikkeling van het begrip dat deelnemers in deze relaties hebben van hun partner, de relatie en de omgeving waarin deze zich ontwikkelt. We hebben voorts beschreven op welke wijzen de cognitieve functie van onderhandelings- en contracteringsprocessen de prestaties van samenwerkingsverbanden beïnvloedt. We hebben onder meer de effecten van begrip op impliciete en expliciete beheersing en coördinatie de revue laten passeren en we hebben consequenties als een vermindering van onbegrip en misinterpretatie alsmede mogelijkheden voor het identificeren van kansen besproken.
Daarmee biedt het artikel onderzoekers, managers en adviseurs een beter inzicht in de cognitieve functie van contracten en de processen waardoor deze tot stand komen.

Dr. ir. P.W.L. Vlaar is verbonden aan de Vrije Universiteit

Amsterdam.

Prof. dr. H.W. Volberda en Prof. dr. F.A.J. van den Bosch zijn

verbonden aan de Rotterdam School of Management,

Erasmus Universiteit. 
- Avadikyan, Arman, Patrick Llerena, Mireille Matt, Anne Rozan, en Sandrine Wolff. 2001. 'Organisational rules, codification and knowledge creation in inter-organisation cooperative agreements'. Research Policy 30: 1443-1458. - Blomqvist, Kirsimarja, Pia Hurmellina, en Risto Seppänen. 2005. 'Playing the collaboration game right - balancing trust and contracting'. Technovation 25: 497-504.

Boisot, Max, en J ohn Child. 1999. 'Organizations as adaptive systems in complex environments: The case of China'. Organization Science 10/3: 237-252.

-Campbell, Donald J . 1988. 'Task complexity: A review and analysis'. Academy of Management Review 13: 40-52

- Carson, Stephen I ., Anoop Madhok, en Tao Wu. 2006. 'Uncertainty, opportunism and governance: The effects of volatility and ambiguity on formal and relational contracting'. Academy of Management J ournal. Delmar, Frédéric, en Scott A. Shane. 2003. 'Does business planning facilitate the development of new ventures?' Strategic Management J ournal 24: 1165-1185. Doz, Yves L. 1996. 'The evolution of cooperation in strategic alliances: Initial conditions or learning processes?' Strategic Management J ournal 17: 55-83.

- Eccles, Robert G., en Nitin Nohria. 1992. Beyond the hype: Rediscovering the essence of management. Boston: HBS.

-Fiss, Peer C., en Edward J . Zajac. 2006. 'The symbolic management of strategic change: Sensegiving via framing and decoupling'. Academy of Management J ournal. -Foss, N.J . 1999. Capabilities, confusion, and the costs of coordination: on some problems in recent research on inter-firm relations, Keynote Speech for the Conference on "Cooperation Industrielle: Diversité and Synthese", Paris.

Foss, N.J . and P.G. Klein. 2008. Entrepreneurship: from opportunity discovery to judgment. SMG Working Paper No. 5/2008. Gomes-Casseres, Benjamin. 1996. The alliance revolution. Cambridge: Harvard University Press

Gouldner, Alvin W. 1954. Patterns of industrial bureaucracy. New York: Free Press. - ap, Sandy D. 2001. "Pie sharing" in complex collaboration contexts'. J ournal of Marketing
Research 38: 86-99

- Katz, Daniel, en Robert L. Kahn. 1966. The social psychology of organizations. New York: J ohn Wiley.

- Ketokivi, Mikko, en Xavier Catañer. 2004. 'Strategic planning as an integrative device'. Administrative Science Quarterly 49: 337-365. - Klein Woolthuis, Rosalinde, Bas Hillebrand, en Bart Nooteboom. 2005. 'Trust, contract and relationship development'. Organization Studies 26/6: 813-840

Kumar, R. and P.H. Andersen. 2000. Inter firm diversity and the management of meaning in international strategic alliances. International Business Review, 9: 237-252.

Lui, Steven S., en Hang-Yue Ngo. 2004. 'The role of trust en contractual safeguards on cooperation in non-equity alliances'. J ournal of Management 30: 471-485.

Maitlis, Sally. 2005. 'The social processes of organizational sensemaking'. Academy of Management J ournal 48: 21-49.

- Mayer, Kyle J ., en Nicholas S. Argyres. 2004. 'Learning to contract: Evidence from the personal computer industry'. Organization Science 15: 394-410.

- Nellore, Rajesh. 2001. 'Validating specifications: Contract-based approach'. IEEE Transactions on engineering management 48/4: 491-504.

- Ness, Håvard. 2002. 'Ex post contractual adjustments in dyadic interfirm relations'. Paper presented at the $12 \mathrm{~h}$ Nordic Workshop on Interorganizational Research. Kolding.

- Porac, J oseph F., Marc ] . Ventresca, en Yuri Mishina. 2002. IInterorganizational cognition and interpretation' in The Blackwell Companion to Organizations. J . Baum (ed), 579-598. Oxford: Blackwell.

- Putnam, Linda L. 2003. 'Dialectical tensions and rhetorical tropes in negotiations'.

Organization Studies 25/ 1: 35-53.

Rico, R., Sánchez-Manzanares, M., Gil, F. and Gibson, C. 2008. Team implicit coordination processes: a team knowledge-based approach, Academy of Management Review, 33(1): 163-184. Ring, Peter Smith. 2000. 'The three T's of alliance creation: Task, team and time'. European Management J ournal 18: 153-162. - Ring, Peter Smith, en Andrew H. Van de Ven. 1994. 'Developmental processes of cooperative interorganizational relationships'. Academy of
Management Review 19: 90-118.

- Shankarmahesh, Malesh N., J ohn B. Ford, en Michael S. LaTour. 2004. 'Determinants of satisfaction in sales negotiations with foreign buyers: Perceptions of US export executives'. International Marketing Review 21/4: 423-446. Sutcliffe, Kathleen M., en George P. Huber. 1998. 'Firm and industry as determinants of executive perceptions of the environment'. Strategic Management J ournal 19: 793-807. - Sutcliffe, Kathleen M., en Gerry M. McNamara. 2001. 'Controlling decision- making practice in organizations'. Organization Science 12/4: 484-501

-Thomas, J ames B., en Linda K. Trevino. 1993 'Information-processing in strategic alliance building: A multiple case approach'. J ournal of Management Studies 30: 779-814.

- Vaara, Eero. 2003. 'Post-acquisition integration as sensemaking: Glimpses of ambiguity, confusion, hypocrisy, and politicization' J ournal of Management Studies 40: 859-894. Vlaar, P.W.L. (2008), Contracts and trust in alliances: creating, appropriating and discovering value. Northampton: Edward Elgar.

- Vlaar, P.W.L., P.C. Van Fenema \& V. Tiwari (2008). Co-creating understanding and value in distributed work: how members of onsite and offshore vendor teams give, make, demand and break sense. MIS Quarterly, 32 (2): 227-255.

- Vlaar, P.W.L., F.A.J . Van den Bosch \& H.W. Volberda (2006). Coping with problems of understanding in interorganizational relationships: using formalization as a means to make sense. Organization Studies, 27: 1617-1638.

- Weick, Karl E. 1969/1979 The social psychology of organizing. Reading: Addison-Wesley. Weick, Karl E. 1995. Sensemaking in organizations. London: Sage.

Weick, Karl E. 2001. Making sense of the organization. Oxford: Blackwell.

- Weick, Karl E, en Roberts, Karlene H. 1993.

'Collective mind and organizational reliability:

The case of flight carrier operations on an aircraft carrier deck'. Administrative Science Quarterly 38: 357-381.

- Yakura, Elaine K. 2002. 'Charting time: Timelines as temporal boundary objects'. Academy of Management J ournal 45/5: 956-970.

Zollo, Maurizio, en Sidney G. Winter. 2002 'Deliberate learning and the evolution of dynamic capabilities'. Organization Science 13: 339-351 